\title{
'Ramoso de Brasília': nova cultivar de couve-brócolos.
}

\author{
Paulo Eduardo de Melo; Leonardo de B. Giordano.
}

Embrapa Hortaliças, C. Postal 218, 70.359-970 Brasília - DF. E.mail: paulo@cnph.embrapa.br; cnph@cnph.embrapa.br

\section{RESUMO}

Com o objetivo de desenvolver novas cultivares de couve-brócolos que pudessem servir como opção de plantio para os produtores, foi iniciado em 1984 um programa de melhoramento de couve-brócolos na Embrapa Hortaliças. Por meio desse programa, desenvolveu-se a cultivar de polinização aberta denominada 'Ramoso de Brasília', obtida após seis ciclos de seleção entre e dentro de linhagens desenvolvidas a partir das melhores plantas de uma população coletada em Itapecerica da Serra (SP). A cultivar Ramoso de Brasília é recomendada para cultivo de inverno, podendo também ser utilizada em verões amenos. É precoce e bastante produtiva. Apresenta grande número de ramificações laterais tenras e longas, cujo comprimento facilita a colheita. As inflorescências são verde-brilhantes, com ótimo aspecto comercial e excelente qualidade após cocção. Em plantios realizados em Brasília, tem-se observado menor ocorrência de podridão-mole nas inflorescências em campo e melhor conservação pós-colheita. Sementes da cultivar Ramoso de Brasília podem ser adquiridas no comércio em geral ou obtidas, em pequenas quantidades, na Embrapa Hortaliças.

Palavras-chave: Brassica oleracea var. italica, melhoramento, colheita, pós-colheita, qualidade.

\section{ABSTRACT}

'Ramoso de Brasília': a new broccoli cultivar.

In 1984, a sprouting broccoli breeding program was iniciated at Embrapa Hortaliças, with the aim of developing new cultivars as options for producers. This breeding program resulted in the open-pollinated cultivar named Ramoso de Brasília, developed through six cycles of selection between and within full-sib families derived from the elite plants of a population collected at the Itapecerica da Serra county, state of São Paulo. 'Ramoso de Brasília' is recommended for Brazilian winter cropping, although it can also be used in mild summer conditions. With a short cycle and high yielding, the cultivar also shows a high number of lateral sprouts, with soft and long stems, making harvesting much easier. Inflorescences are bright-green and show excellent market appearance, as well as high quality after cooking. In plantings made in Brasília, low occurrence of inflorescence soft-rot and longer post-harvest conservation were observed. 'Ramoso de Brasília' seeds are available on the market or, in small samples, at Embrapa Hortaliças.

Keywords: Brassica oleracea var. italica, breeding, harvest, postharvest, quality.

(Aceito para publicação em 22 de março de 1999)

\begin{abstract}
A couve-brócolos, juntamente com repolho e a couve-flor, compõe o grupo das Brássicas de consumo mais generalizado como hortaliças pela população brasileira. Ao contrário das duas últimas porém, não existe um grande número de cultivares de couve-brócolos disponível aos produtores como opção de plantio. Por este motivo, em 1984 foi iniciado na Embrapa Hortaliças um programa de melhoramento de couvebrócolos com o objetivo de desenvolver cultivares que fossem melhor adaptadas às condições de produção e que permitissem a ampliação das épocas e das regiões de cultivo dessa hortaliça, no Brasil. Nesse programa foram desenvolvidos diversos genótipos de características superiores, exemplificando-se a cultivar Ramoso de Brasília.
\end{abstract}

\section{ORIGEM}

Ramoso de Brasília é uma cultivar de couve-brócolos de polinização aberta, do tipo ramoso. A população inicial, que deu origem à cultivar, foi coletada em 1984, em Itapecerica da Serra (SP), em uma ação conjunta entre a UNESP Campus de Botucatu e a Embrapa Hortaliças. Sementes dessa população foram plantadas em Brasília, sendo realizados seis ciclos de seleção entre e dentro de famílias de irmãos germanos. Em

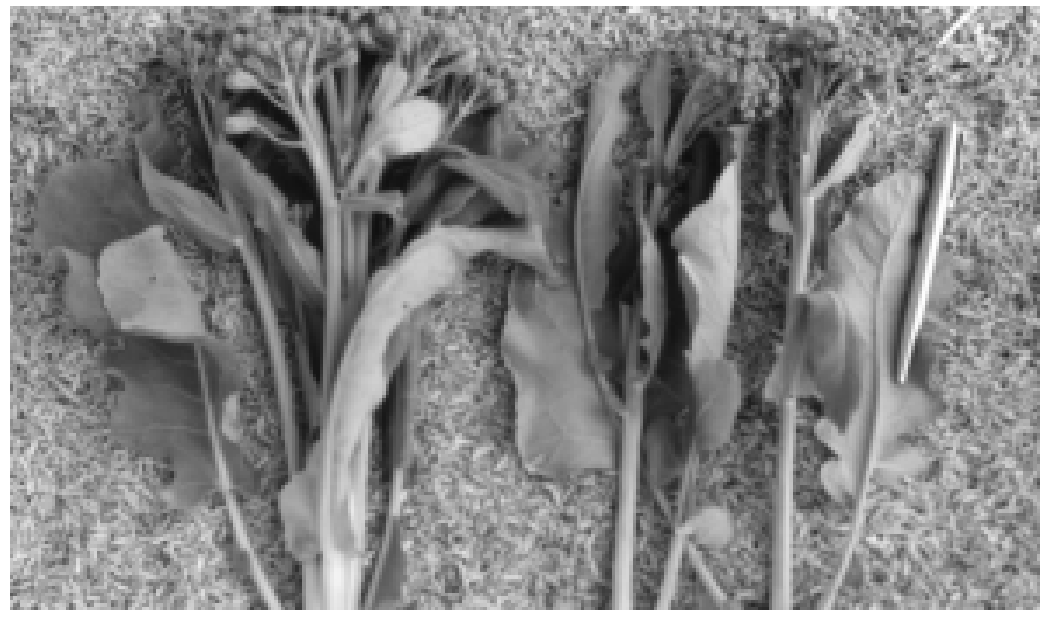

1992, sementes das melhores famílias foram distribuídas a produtores de Brasília, que, em conjunto com a Embrapa Hortaliças, identificaram a mais promissora. Em 1993, essa família foi novamente avaliada por produtores e, ante os resultados positivos, decidiu-se pela sua liberação como cultivar, recebendo o nome Ramoso de Brasília.

\section{DESCRIÇÃO}

As plantas da cultivar Ramoso de Brasília são de porte pequeno contendo folhas verde-escuras, com formação de grande número de ramificações laterais. As hastes são longas, apresen- tando cerca de $30 \mathrm{~cm}$. Além de serem tenras, têm boa textura após cocção, cuja coloração torna-se verde-brilhante. As inflorescências são também verde-brilhantes e de formato convexo, apresentando, assim como as hastes, excelente textura após o cozimento. $\mathrm{O}$ ciclo é bastante precoce, com a primeira colheita acontecendo em torno de 80 dias após a semeadura. Devido à boa capacidade de formar ramos laterais, as plantas da cultivar Ramoso de Brasília podem permanecer em produção e colheita por períodos de até 60 dias após a primeira colheita. 


\section{CARACTERÍSTICAS AGRO- NÔMICAS E COMERCIAIS}

A cultivar Ramoso de Brasília é originalmente recomendada para plantios de inverno, podendo ser cultivada também em condições de verão ameno. $\mathrm{O}$ formato convexo da inflorescência permite o escoamento da água da chuva ou irrigação, tendo sido observada em campo uma redução acentuada de podridão-mole na inflorescência. O espaçamento recomendado para plantio é de $80 \times 50 \mathrm{~cm}$, um pouco mais adensado que o tradicionalmente utilizado para outras cultivares. Esse adensamento é possível devido ao menor porte das plantas da cultivar Ramoso de Brasília o que se traduz em maior produtividade por área. Durante o período de avaliação da cultivar em Brasília, obteve-se uma produtividade média de 18 t/ha, bastante significativa se comparada à produtividade alcançada, nas mesmas condições, com outras cultivares, inclusive híbridas, que variou entre 9 e 16 t/ha. Os demais tratos culturais são semelhantes àqueles normalmente utilizados para as demais cultivares.

Além das vantagens já mencionadas, observou-se ainda que a colheita de inflorescências na cultivar Ramoso de Brasília é bastante facilitada pelo comprimento longo das hastes, sendo feita muito mais rapidamente que nas demais cultivares. Além disso, os produtores que participaram da avaliação experimental da cultivar notaram que as inflorescências, uma vez atingido o ponto de colheita, mesmo que não sejam colhidas, permanecem com os botões florais fechados por mais tempo que as cultivares tradicionalmente utilizadas. Essa característica não compromete a qualidade das hastes e inflorescências, que permanecem tenras enquanto os botões florais estiverem fechados e permite maior flexibilidade na execução da colheita. Observou-se também que a cultivar Ramoso de Brasília apresenta inflorescências de melhor conservação pós-colheita, mantendo-se verdes, com aspecto de recém-colhidas, por um período mais longo.

\section{DISPONIBILIDADE DE SE- MENTES}

Quantidades maiores de sementes da cultivar Ramoso de Brasília podem ser adquiridas no comércio em geral, em boas casas de sementes ou produtos agropecuários. Pequenas quantidades, em amostras de até $3 \mathrm{~g}$, podem ser obtidas junto à Embrapa Hortaliças, mediante solicitação pessoal ou por carta, fax, telefone ou correio eletrônico.

BRUNE, S.; MELO, P.E. de; ÁVILA, A.C. de. Novos progenitores de batata imunes a PVY e PVX e resistentes à pinta-preta. Horticultura Brasileira, Brasília, v. 17, n. 2, p. 173-174, julho 1999.

\title{
Novos progenitores de batata imunes a PVY e PVX e resistentes à pinta-preta.
}

\author{
Sieglinde Brune; Paulo Eduardo de Melo; Antônio Carlos de Ávila. \\ Embrapa Hortaliças, C. Postal 218, 70.359-970 Brasília-DF. E.mail: linde@cnph.embrapa.br.
}

\section{RESUMO}

As viroses que ocorrem com muita frequência em plantas de batata no Brasil são responsáveis por queda na produtividade, principalmente quando provocados por uma combinação de vírus. Para PVY e PVX o tipo de resistência usada é a imunidade, controlada por genes simples e dominantes. A pinta-preta, causada pelo fungo Alternaria solani, é uma das principais doenças fúngicas da batata em condições de alta umidade e temperatura, podendo causar até $73 \%$ de perdas na produtividade. O uso da resistência genética é de grande interesse agronômico, uma vez que a eliminação ou redução do uso de agrotóxicos leva a menores custos de produção da lavoura, além de mitigar a poluição ambiental e os riscos ao ser humano. A Embrapa Hortaliças avalia anualmente, em seu programa de melhoramento da batata, a imunidade aos vírus PVY e PVX, a resistência à pinta-preta, além de observar as características agronômicas dos clones. Entre os genótipos avaliados em 1991 e 1992 destacaram-se os clones Embrapa/CIP-PP063 e Embrapa/CIP-PP084 com boas características agronômicas, imunidade a PVY e PVX e alto nível de resistência à pinta-preta. Ambos podem ser empregados como progenitores em programas de melhoramento que objetivem imunidade a esses vírus e resistência à pinta-preta. Os clones Embrapa/CIP-PP063 e o Embrapa/CIP-PP084 encontram-se à disposição de instituições interessadas em trabalhos cooperativos com a Embrapa Hortaliças, na forma de tubérculos ou plântulas in vitro.

Palavras-chave: Solanum tuberosum, Alternaria solani, germoplasma, fungo, melhoramento, PVY, PVX.

\section{ABSTRACT}

New potato progenitors immune to $\mathrm{PVY}$ and PVX, and resistant to early blight.

Viruses that occur frequently in potato crops in Brazil are responsible for crop yield losses, mainly when caused by a combination of viruses. For PVY and PVX the type of resistance used is immunity, controlled by single and dominant genes. Early blight caused by Alternaria solani is one of the most important potato diseases in Brazil, especially when high air humidity and warm weather conditions prevail. This disease can cause losses up to $73 \%$. The use of resistant varieties is an efficient control measure, being simultaneously harmless to environment and humans and providing an expressive reduction in costs. Genetic resistance has also the advantage that it can be used in association with other control methods in integrated disease management. In the potato breeding program, Embrapa Hortaliças annually evaluates the immunity to PVY and PVX, the resistance to early blight and agronomic traits. Among the clones evaluated in 1991 and 1992, 'Embrapa/CIP-PP063' and 'Embrapa/CIP-PP084' stood out with good agronomical characteristics, immunity to PVY and PVX, and high levels of resistance to early blight. Both are recommended for use as parents in breeding programs for resistance to early blight. Clones Embrapa/ CIP-PP063 and Embrapa/CIP-PP084 are available for cooperative work with other institutions, as in vitro plantlets or tubers.

Keywords: Solanum tuberosum, Alternaria solani, germplasm, fungus, breeding, PVY, PVX. 